\title{
CARACTERIZAÇÃO MORFOMÉTRICA DA BACIA HIDROGRÁFICA DO RIACHO RANGEL-PIAUÍ, BRASIL
}

\author{
Gustavo Cassiano da Silva , Fillipe de Paula Almeida ${ }^{2}$, Rherison Tyrone Silva \\ Almeida $^{3}$, Marcio Mesquita ${ }^{4}$, José Alves Junior ${ }^{4}$ \\ ${ }^{1}$ Doutorando do Programa de Pós-Graduação em Agronomia, Universidade Federal \\ de Goiás, Goiânia, GO, Brasil - gustavo.cassred@hotmail.com \\ ${ }^{2}$ Mestrando do Programa de Pós-Graduação em Agronomia, Universidade Federal \\ de Goiás, Goiânia, GO, Brasil \\ ${ }^{3}$ Doutor em Agronomia, Faculdade Unida de Campinas, Goiânia, GO, Brasil. \\ ${ }^{4}$ Professor Doutor do Programa de Pós-Graduação em Agronomia, Universidade \\ Federal de Goiás, Goiânia, GO, Brasil
}

Recebido em: 22/09/2018 - Aprovado em: 23/11/2018 - Publicado em: 03/12/2018 DOI: 10.18677/EnciBio_2018B22

\begin{abstract}
RESUMO
As características morfométricas de uma bacia hidrográfica constituem elementos indispensáveis para o planejamento e avaliação do seu comportamento hidrológico, e auxilia nas tomadas de decisões quanto à conservação, uso e ocupação das terras. Neste sentido, este estudo teve como objetivo analisar os dados de morfometria da bacia hidrográfica do riacho Rangel, que é um dos principais afluentes do rio Gurguéia, que abastece todo Sul do estado do Piauí, por meio da caracterização morfometria, considerando a geometria, o relevo e a drenagem. Como resultado obtido verificou-se que a bacia apresentou drenagem de $326,18 \mathrm{~km}^{2}$ e o perímetro de 109,42 km, sendo caracterizada como uma bacia de médio porte. Apresentou formato alongado e que juntamente com a avaliação de índices de relevo e hidrografia, mostrou-se pouco favorável a inundações, sendo classificada como de $4^{\underline{a}}$ ordem. A bacia apresenta baixas densidades de drenagem e hidrográfica, elevada permeabilidade do solo, possui canais retilíneos e com baixa declividade. Desse modo, as análises morfométricas permitiram compreender sobre as dinâmicas dos processos hidrológicos contribuindo para o manejo racional do uso do solo e da água na bacia hidrográfica.
\end{abstract}

PALAVRAS-CHAVE: Morfometria, recursos hídricos, sistema de informações geográficas

\section{MORPHOMETRIC CHARACTERIZATION OF THE WATERSHED RIACHO RANGEL - PIAUÍ, BRAZIL}

\begin{abstract}
The physical characteristics of a river basin are indispensable elements for the planning and evaluation of its hydrological behavior, and assists in the decision making regarding the conservation, use and occupation of the lands. In this sense, this study aimed to analyze the morphometric data of the Rangel stream, which is one of the main tributaries of the Gurguéia river, which supplies all the South of the
\end{abstract}


state of Piauí, through the morphometric characterization, considering the geometry, the relief and drainage. As a result, it was verified that the basin presented a drainage of $326.18 \mathrm{~km}^{2}$ and the perimeter of $109.42 \mathrm{~km}$, being characterized as a medium-sized basin. It presented an elongated shape and, together with the evaluation of relief and hydrography indices, proved to be unfavorable to floods, being classified as 4th order. The basin presents a low drainage density, high soil permeability and small hydrographic density, presenting rectilinear and low slope channels. Thus, the morphometric analysis allowed understanding of the dynamics of hydrological processes contributing to the rational management of land use in the river basin.

KEYWORDS: Morphometry; water resources; geographic information system

\section{INTRODUÇÃO}

O crescimento populacional acelerado consequentemente vem provocando a expansão das áreas agrícolas por maior necessidade de produção de alimentos. Nesse sentido, o uso imprescindível e exaustivo do solo e da água, adicionado ao manejo operacional inadequado desses elementos vêm causando problemas e/ou desequilíbrios dos recursos naturais e na sustentabilidade ambiental, tais como; degradação do solo, aumento da área impermeabilizada nas bacias hidrográficas, assoreamento dos leitos dos rios, poluição dos corpos de água, escassez hídrica, entre outros (VASCO et al., 2011).

Teodoro et al. (2007) salientam que a bacia hidrográfica é o espaço territorial natural da efetiva movimentação e fenomenologia do ciclo hidrológico, sendo composta por um conjunto de redes de drenagem formada por cursos de água que confluem até resultar em um único leito e ponto de saída (exutório). As características do solo, relevo, cobertura vegetal, entre outros, são fatores que interferem na dinâmica do ciclo hidrológico (BOTELHO, 2015). O que justifica necessidade constante e indispensável de estudos em bacias hidrográficas para fundamentar a exploração sustentável dos recursos naturais e ambientais (VASCO et al., 2011).

Rocha et al. (2014) enfatizam que a base dos estudos sobre a sustentabilidade fundamenta-se no entendimento da dinâmica dos recursos hídricos e do desenvolvimento da gestão desses recursos nas bacias hidrográficas, considerando as relações antrópicas, econômicas e socioambientais.

A caracterização morfométrica de uma bacia hidrográfica é um procedimento executado nas análises hidrológicas e/ou ambientais, tendo como objetivo esclarecer questões sobre o entendimento das dinâmicas, locais e regionais, da infiltração, quantidade de deflúvio, evapotranspiração, e do escoamento superficial e subsuperficial associando a elementos físicos e bióticos de uma bacia hidrográfica. Esta caracterização serve como instrumento para aplicações quantitativas relacionadas aos recursos hídricos, e à dinâmica ambiental, possibilitando o melhor gerenciamento e aproveitamento dos recursos naturais e nas limitações quanto aos usos (SILVA et al., 2014; FRAGA et al., 2014).

Neste contexto, destaca-se a bacia hidrográfica do riacho Rangel, um dos principais afluentes do rio Gurguéia, o qual representa a segunda maior bacia hidrográfica do estado do Piauí. O rio Gurguéia é o principal afluente da Região Hidrográfica do Parnaíba, no Nordeste Brasileiro, com uma população, aproximada, de 1.3 milhões de habitantes. A bacia em estudo apresenta uma vasta rede hidrológica, com área de drenagem de $326.18 \mathrm{~km}^{2}$, logo, com grande potencial 
econômico, desde transporte fluvial, pesca, pecuária, lazer, turismo e agricultura, que pode contribuir com rendas de subsistência familiar, além da importância no papel ecológico sobre o ecossistema dos biomas cerrado e caatinga (IBGE, 2017).

Assim, danos causados na bacia do Riacho Rangel podem afetar significativamente a quantidade e qualidade da água que abastece a macrorregião do Nordeste Brasileiro. Guimarães (2014) evidenciou que essa região vem sendo afetada com o desmatamento e com o manejo inadequado do uso do solo e das águas.

Diante do exposto, buscando contribuir para o entendimento das consequências hidrológicas, o presente trabalho teve como objetivo, analisar as características morfométricas da bacia do riacho Rangel, com base em técnicas de geoprocessamento, proporcionando, assim, subsídios adicionais à sua gestão.

\section{MATERIAL E MÉTODOS}

O presente estudo foi realizado na bacia do riacho Rangel, localizada no Sul do estado do Piauí (PI). As coordenadas geográficas compreendem 9 43' 43" S de latitude e $44^{\circ} 28^{\prime} 00^{\prime \prime} \mathrm{W}$ de longitude, localiza-se entre os municípios de Curimatá e Redenção do Gurguéia (Figura 1).

O clima predominante é tropical semiárido quente (Koppen), caracterizado por duas estações bem definidas, com verão chuvoso e inverno seco, com duração de seis meses e precipitação anual média acima de 800 . A vegetação característica da região é por formação de Cerrado e Caatinga, tendo como principais atividades econômicas a agricultura, pecuária e pesca (BOTREL et al., 2015).

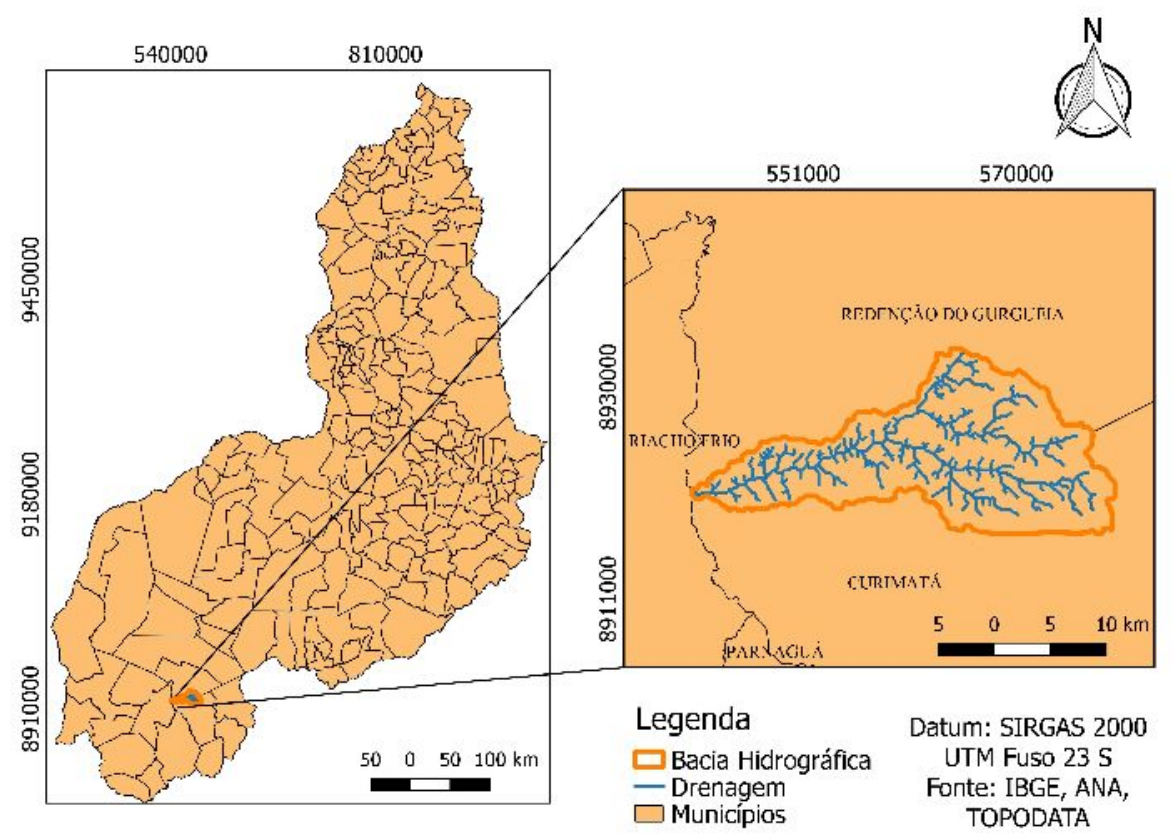

FIGURA 1 Localização da bacia do Riacho Rangel, no estado do Piauí, Brasil.

FONTE: Elaborado a partir do SRTM disponibilizado pela EMBRAPA Monitoramento por Satélite -TOPODATA (MIRANDA, 2005).

Os mapeamentos foram realizados com auxílio do software QGIS 2.18.3, que foi integrado com o GRASS GIS 7.2.0, através de complementos, possibilitando 
organizar, processar, analisar, mapear e interpretar os dados geográficos pertinentes à bacia do riacho Rangel.

Os limites da bacia hidrográfica, bem como a rede de drenagem foram obtidos por meio da ferramenta r.watershed do GRASS GIS, tendo por entrada o Modelo Digital de Elevação (MDE) com resolução espacial de 30 metros obtido através do TOPODATA. Por meio da ferramenta r.to.vect procedeu-se a conversão dos dados para o formato vetorial, que, por sua vez, permitiu o levantamento das características geométricas da bacia hidrográfica,

Com o intuito de caracterizar a evolução da cobertura do solo, foram elaborados mapas em três interstícios temporais, 2003, 2010 e 2017, a partir do sensor OLI do satélite Landsat 8 para 2017 com resolução espacial de 15 metros, obtida através de fusão da composição colorida com a banda pancromática através do complemento Orfeo Monteverdi, e do sensor TM do satélite Landsat 5 com resolução espacial de 30 metros para 2003 e 2010. Foi utilizado o complemento Orfeo e feita a classificação não supervisionada "Kmeans" do software QGIS versão 2.18.13.

Para as análises dos parâmetros físicos da bacia, foram utilizadas as seguintes características morfométricas: Área da bacia $(A)$, Perímetro $(P)$, Comprimento axial (La), Comprimento do canal principal (L), Comprimento total dos canais (Lt), Coeficiente de manutenção $(\mathrm{Cm})$, Índice de rugosidade (Ir), Coeficiente de compacidade $(\mathrm{Kc})$, Índice de circularidade (Ic), Fator de forma (Ff), Índice de sinuosidade (Is), Densidade da drenagem (Dd), Densidade hidrográfica (Dh), Ordem de canais (STRAHLER, 1952), Amplitude altimétrica $\left(H_{m}\right)$.

O Coeficiente de manutenção, segundo Schumm (1956), é calculado pela relação inversa da densidade de drenagem e que fornece a área mínima necessária para a manutenção de um metro de canal de escoamento, conforme equação 1:

$\mathrm{Cm}=\frac{1}{D d} * 1000$

Onde, $\mathrm{Cm}$ : coeficiente de manutenção $\left(\mathrm{m}^{2} \cdot \mathrm{m}^{-1}\right)$, e $\mathrm{Dd}$ : densidade de drenagem $\left(\mathrm{km} \cdot \mathrm{km}^{-2}\right)$;

Índice de rugosidade (Ir) corresponde ao produto da densidade de drenagem pela declividade média da bacia (FRAGA et al., 2014), equação 2:

Ir $=H m * D d$

Onde: Ir: índice de rugosidade; Hm: amplitude altimétrica $(\mathrm{m})$ e, Dd: densidade de drenagem $\left(\mathrm{km} / \mathrm{km}^{2}\right)$.

O Coeficiente de compacidade $(\mathrm{Kc})$ : é a relação entre a forma da bacia com um círculo, equação 3 :

$K c=0,28 * \frac{p}{\sqrt{A}}$

Onde, Kc: coeficiente de compacidade; P: perímetro (m); A: área de drenagem $\left(\mathrm{m}^{2}\right)$.

O Índice de circularidade (Ic) relaciona a área da bacia à área de um círculo de perímetro igual ao da área da bacia. Foi obtido conforme a equação 4:

lc $=12,57 * \frac{A}{p^{2}}$

Onde, Ic: índice de circularidade; A: área da bacia $\left(\mathrm{km}^{2}\right) ; \mathrm{P}$ : perímetro da bacia $(\mathrm{km})$ ENCICLOPÉDIA BIOSFERA, Centro Científico Conhecer - Goiânia, v.15 n.28; p. 247 
Fator de forma $(\mathrm{Ff})$, segundo Santos et al. (2012) relacionam a forma da bacia com um retângulo, correlacionando a razão entre a largura média e o comprimento axial da bacia da foz até o ponto mais distante do espigão, equação 5 :

$F f=\frac{A}{L a^{2}}$

Onde, Ff: fator forma; A: área da bacia $\left(\mathrm{km}^{2}\right)$ e, La: comprimento axial da bacia $(\mathrm{km})$.

Índice de sinuosidade (Is) relaciona o comprimento verdadeiro do canal (em projeção ortogonal) com a distância vetorial (comprimento em linha reta) entre os dois extremos do canal principal (NARDINI et al., 2013), equação 6:

$I S=\frac{L}{L v}$

Onde, Is: índice de sinuosidade; L: comprimento do rio principal $(\mathrm{km})$ e, Lv: comprimento vetorial do rio principal $(\mathrm{km})$.

Densidade da drenagem (Dd) consiste na razão entre o comprimento total dos canais e a área da bacia hidrográfica. Segundo Christofoletti (1980), o cálculo da densidade é importante para o estudo das bacias hidrográficas por que apresenta relação inversa com o comprimento dos rios. À medida que aumenta o valor numérico da densidade há diminuição quase proporcional do tamanho dos componentes fluviais das bacias de drenagem. Conforme a equação 7:

$\mathrm{Dd}=\frac{\mathrm{Lt}}{\mathrm{A}}$

Onde, Dd: Densidade de drenagem $\left(\mathrm{km} / \mathrm{km}^{2}\right)$; Lt: comprimento total dos canais $(\mathrm{km})$; A: área da bacia $\left(\mathrm{km}^{2}\right)$.

Densidade hidrográfica (Dh) compara a frequência de cursos de água e estima a capacidade de gerar novos cursos de água. Dada pela equação 8:

$\mathrm{Dh}=\frac{\mathrm{N}}{\mathrm{A}}$

Onde, Dh: densidade hidrográfica; N: número de rios ou canais; $A$ : área da bacia $\left(\mathrm{km}^{2}\right)$.

Amplitude altimétrica $\left(\mathrm{H}_{\mathrm{m}}\right)$ é a relação das variações topográficas da bacia e corresponde à diferença altimétrica, em metros, entre a altitude da foz (elevação mínima) e a altitude do ponto mais alto no divisor topográfico (elevação máxima) próximo ao eixo (STRAHLER, 1952). Conforme a equação 9.

$H_{m}=e_{\max }-e_{\min }$

Onde, $H_{m}$ : amplitude altimétrica da bacia $(m)$; $e_{\max }$ : elevação máxima; $e_{\min }$ : elevação mínima.

\section{RESULTADOS E DISCUSSÃO}

A tabela 1 apresenta os valores de áreas quanto ao uso e cobertura do solo da bacia do riacho Rangel, com variações diversificadas. A área de Cerrado ocupa a maior porção da unidade de gestão, com aumento de $125,4 \mathrm{~km}^{2}(38,4 \%)$ no ano de 2003, para 150,54 km² (46,1\%) no ano de 2010 e 209,24 km² (64,1\%) em 2017. Essa projeção de aumento da área de Cerrado indica que essa bacia apresenta uma grande porção de área preservada, como pode ser observado na figura 2. 
O crescimento da área do Cerrado ao longo dos anos se justifica pela ampliação do Parque Nacional da Serra das Confusões no ano de 2010, o qual ficou inserido a Serra Vermelha (próximo a bacia do riacho Rangel), área da nascente, na qual, também se insere na ampliação, com isso contribui para a sustentabilidade e a melhoria da qualidade de água das bacias hidrográficas.

TABELA 1 Uso e cobertura do solo da bacia do Riacho Rangel no estado do Piauí, Brasil.

\begin{tabular}{|c|c|c|c|c|c|c|}
\hline \multirow{2}{*}{ Uso e cobertura do Solo } & \multicolumn{2}{|c|}{2003} & \multicolumn{2}{|c|}{2010} & \multicolumn{2}{|c|}{2017} \\
\hline & Área $\left(\mathrm{km}^{2}\right)$ & Área (\%) & Área $\left(\mathrm{km}^{2}\right)$ & Área (\%) & Área $\left(\mathrm{km}^{2}\right)$ & Área (\%) \\
\hline Cerrado/Caatinga & 125,4 & 38,4 & 150,5 & 46,1 & 209,2 & 64,1 \\
\hline Pastagem & 74,0 & 22,7 & 97,7 & 30,0 & 66,7 & 20,5 \\
\hline Agricultura & 47,4 & 14,5 & 56,6 & 17,4 & 37,6 & 11,5 \\
\hline Mata Ciliar/Galeria & 79,4 & 24,4 & 21,3 & 6,5 & 12,7 & 3,9 \\
\hline Total & 326,2 & 100 & 326,2 & 100 & 326,2 & 100 \\
\hline
\end{tabular}

A segunda maior porção é ocupada pela pastagem que no ano de 2003 , possuía uma área de $74,0 \mathrm{~km}^{2}(22,7 \%)$, em 2010 passou para $97,7 \mathrm{~km}^{2}(30 \%)$ e em 2017 com aproximadamente $66,7 \mathrm{~km}^{2}(20,5 \%)$. Em sequência, tem-se a agricultura, com $47,4 \mathrm{~km}^{2}(14,5 \%)$ no ano de $2003,56,6 \mathrm{~km}^{2}(17,4 \%)$ em 2010 , e $37,6 \mathrm{~km}^{2}$ $(11,5 \%)$ em 2017, respectivamente.

Para os sistemas de cobertura do solo, pastagem e agricultura, ocorreu um aumento da área na bacia até o ano de 2010. Logo após houve um decréscimo, em função do aumento da área preservada nessa região, definida pelo Decreto de 30 de dezembro de 2010, que dispõe sobre a ampliação do Parque Nacional da Serra das Confusões no qual a bacia está inserida (BRASIL, 2010).

A mata ciliar/galeria reduziu entre os anos de 2003 a 2017, de $79,4 \mathrm{~km}^{2}(24,4$ $\%$ da área da bacia) para $12,7 \mathrm{~km}^{2}(3,9 \%)$. A maior devastação da floresta ocorreu entre 2003 e $2010\left(79,4 \mathrm{~km}^{2}\right.$ para $\left.21,3 \mathrm{~km}^{2}\right)$, ocasionada pelo uso da agricultura e pastagem nesse sistema, pois, nessa época não tinha área de preservação.

A presença de atividades agropecuárias nas margens ciliares está relacionada às características dos solos dessa área, os quais possuem condições favoráveis para o desenvolvimento agrícola, tais como, fertilidade, umidade, estabilidade etc. O manejo inadequado nesse sistema de uso do solo pode provocar a compactação dos solos devido ao pisoteio do gado e a utilização de máquinas agrícolas; eutrofização ou contaminação dos cursos d'água devido ao uso de corretivos agrícolas e/ou agrotóxicos para desenvolvimento de culturas; produção de sedimentos (erosão) e deposição nos cursos d'água (assoreamentos) caso não seja realizado o adequado sistema de plantio (plantio direto ou convencional), adotando quando necessário práticas conservacionistas, como, por exemplo, o terraceamento. 

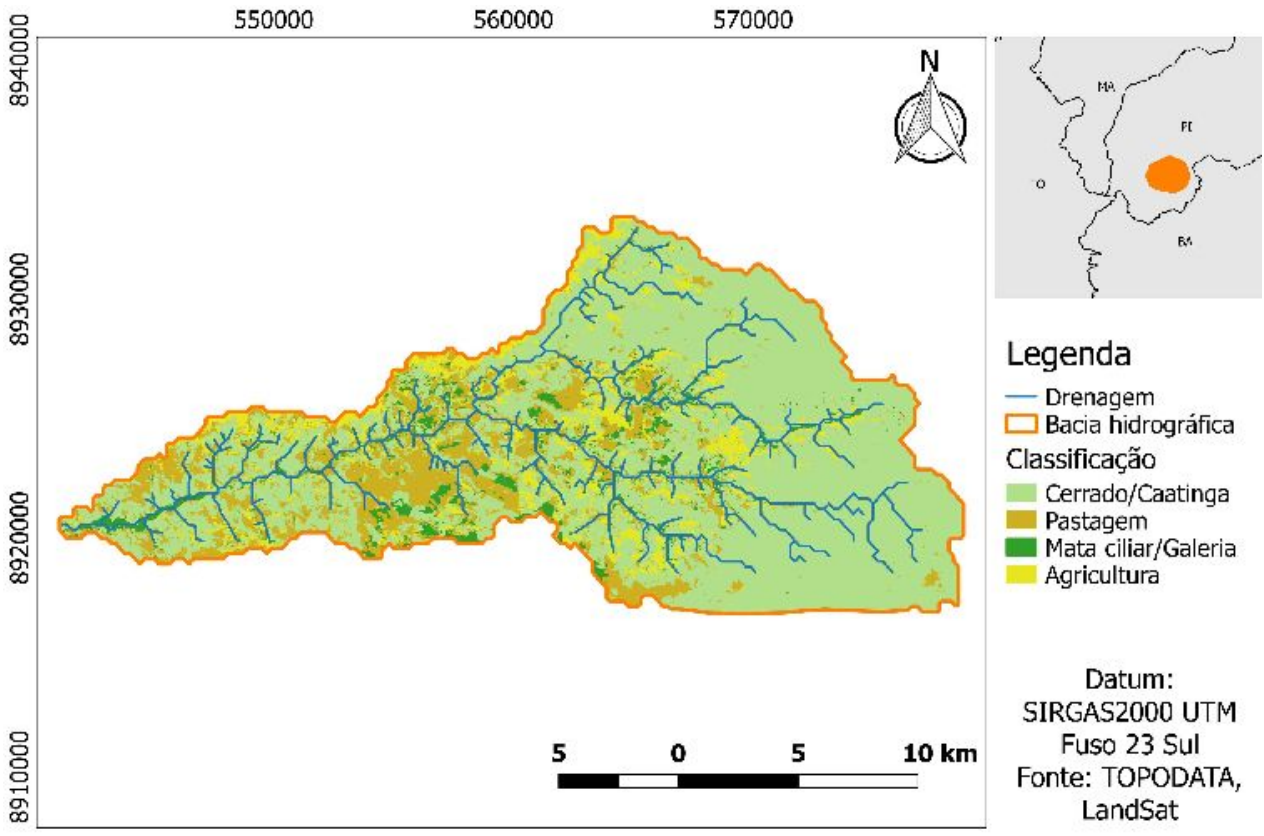

FIGURA 2 Mapa de uso e cobertura do solo da bacia do riacho Rangel, no estado do Piauí, Brasil.

A hipsometria é exibida na figura 3 , verificou-se que a altitude máxima da bacia é de $600 \mathrm{~m}$, a altitude mínima de $300 \mathrm{~m}$, altitude média da bacia de $413 \mathrm{~m}$ e amplitude altimétrica de 351 . A maior área da bacia corresponde a $27 \%$, conforme a tabela 2, encontrada na faixa de altitude de 578 a 600 metros.

Para Gerber et al. (2018), a variação da elevação e a elevação média de uma bacia hidrográfica têm grande correlação com a temperatura e a precipitação. Tais diferenças altimétricas em uma bacia podem ocasionar diferenças relevantes na temperatura média. Isso provoca variações na evapotranspiração e precipitação anual (SANTOS et al., 2012).

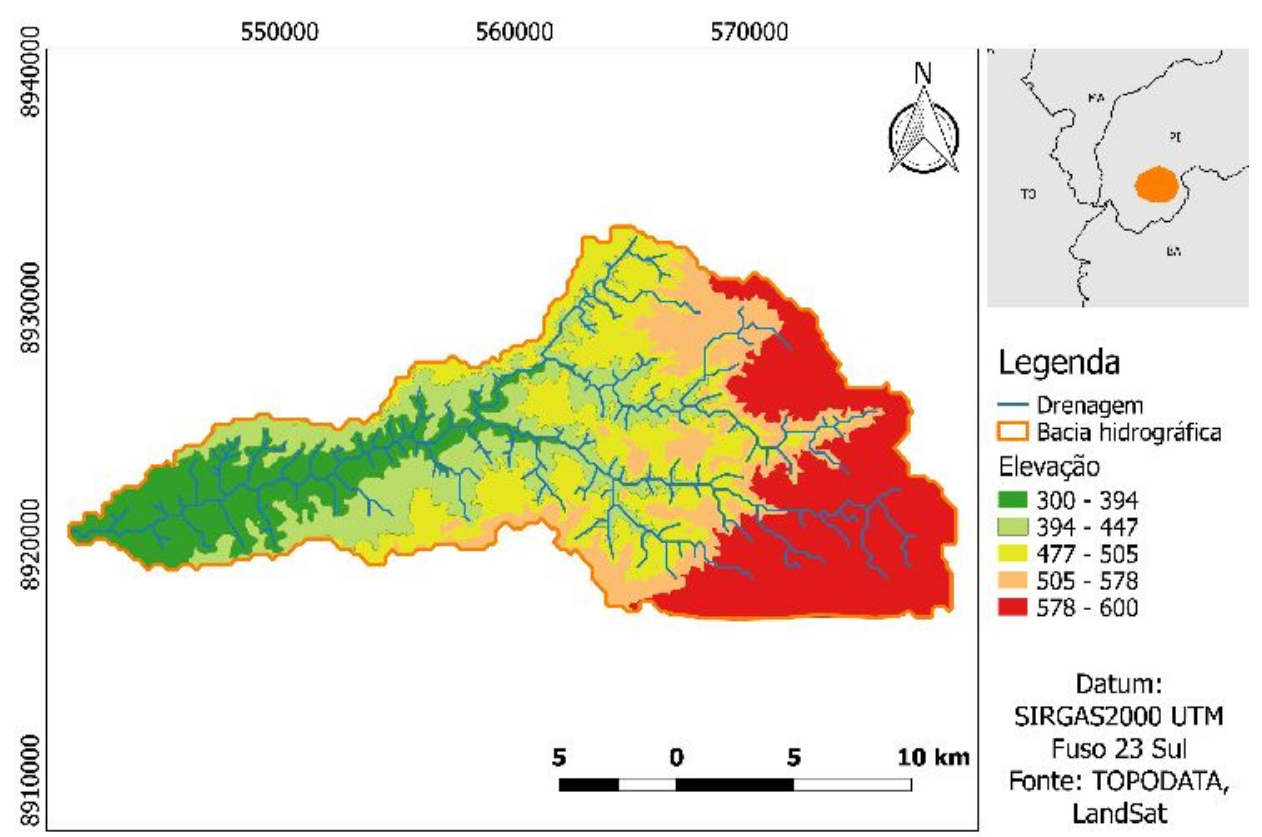

FIGURA 3 Mapa hipsométrico da bacia do Riacho Rangel, no estado do Piauí, Brasil. 
TABELA 2 Distribuição das altitudes da bacia hidrográfica do Riacho Rangel, no estado do Piauí, Brasil.

\begin{tabular}{ccc}
\hline Altitude & Área $\left(\mathrm{km}^{2}\right)$ & $\%$ \\
\hline $300-394$ & 49,75 & 15 \\
\hline $394-447$ & 70,77 & 22 \\
\hline $447-505$ & 70,78 & 22 \\
\hline $505-578$ & 47,09 & 14 \\
\hline $578-600$ & 87,71 & 27 \\
\hline
\end{tabular}

A declividade pode ser influenciada pela relação entre a precipitação e o deflúvio da bacia hidrográfica, o que pode interferir na velocidade de escoamento superficial e infiltração de água no solo, e que pode ser amenizado pela cobertura vegetal. Na bacia em estudo, de acordo com a figura 4 e tabela 3, verificou-se predominância das classes de relevo muito baixa, com valores de 56,82\% $(185,32$ $\mathrm{km}^{2}$ ) da área total da bacia. Para a classe de relevo alta a área total é de 10,29 km² cerca de $3,15 \%$. As demais classes de relevo da bacia são classificadas como baixa e média que representam $88,87 \mathrm{~km}^{2} \quad(27,25 \%), 41,70 \mathrm{~km}^{2} \quad(12,78 \%)$, respectivamente.

Nas áreas que apresentam declividade baixa e muito baixa podem ser desenvolvidas atividades como a agricultura e a pecuária utilizando-se práticas simples de manejo do solo (MIOTO et al., 2017), sendo esta, menos propensa a erosão e aumentando a possibilidade de infiltração no solo (BARRETO et al., 2017). Assim, a declividade e a cobertura vegetal tornam-se fatores importantes na tomada de decisão de um manejo adequado da bacia hidrográfica, visto que influenciam a precipitação efetiva, escoamento superficial e fluxo de água no solo, dentre outros.

Carvalho et al. (2014), obtiveram resultados diferentes aos da bacia do riacho Rangel, tendo como objetivo caracterizar a morfometria da bacia hidrográfica do córrego Santa Maria - ES, verificaram declividade entre $20-45$ e $45-75 \%$ de inclinação, com representatividade de 44,17 e $19,97 \%$ do total da bacia, o que, conforme, caracteriza declividade alta, que são características que contribuem no processo de erosão e sedimentação dos canais de água.

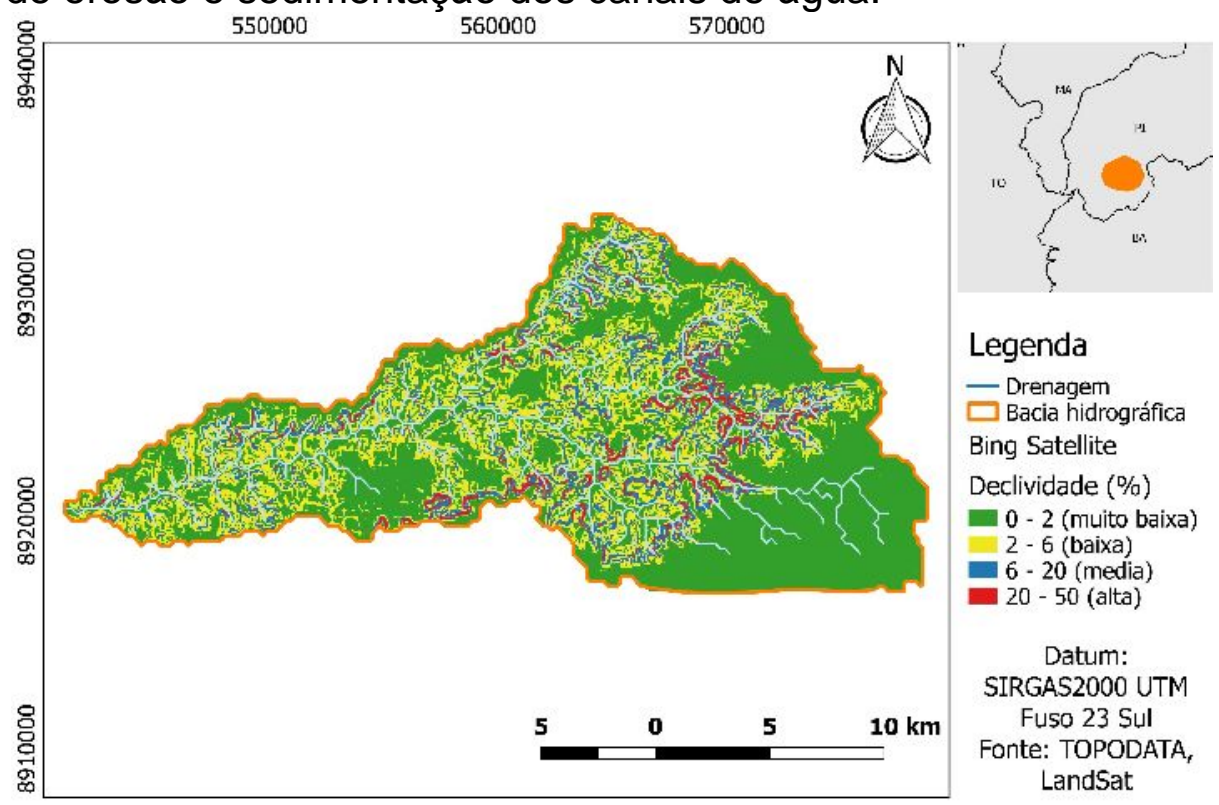

FIGURA 4 Mapa de declividade da bacia do Riacho Rangel, no estado do Piaui - Brasil, conforme metodologia (ALVES SOBRINHO et al., 2010). 
TABELA 3 Classes de declividade em \% e relevo na bacia do Riacho Rangel, município de Redenção do Gurguéia (PI), com áreas correspondentes $\mathrm{em} \mathrm{km} \mathrm{km}^{2} \mathrm{em}$.

\begin{tabular}{cccc}
\hline Declividade $(\%)$ & Relevo & Área $\left(\mathrm{Km}^{2}\right)$ & Área $(\%)$ \\
\hline $0-2$ & Muito baixa & 185,32 & 56,82 \\
\hline $2-6$ & Baixa & 88,87 & 27,25 \\
\hline $6-20$ & Média & 41,70 & 12,78 \\
\hline $20-50$ & Alta & 10,29 & 3,15 \\
\hline
\end{tabular}

Na tabela 4 são apresentados os resultados da caracterização morfométrica da bacia hidrográfica, com um total de 17 variáveis levantadas e analisadas, que possuem importante papel nos processos hidrológicos, passível de ser identificado, quantificado, classificado e caracterizado.

A bacia do riacho Rangel drena uma área total de $326,18 \mathrm{~km}^{2}$, com perímetro de 109,42 km. Trata-se, portanto, de uma unidade hidrológica de média dimensão, que sofreu processos de desmatamento para exploração de madeira, e que nos dias atuais se inserem em áreas protegidas por lei. Então, estudos aprofundados acerca dos recursos hídricos, ecossistemas e uso do solo são necessários, buscando possibilidades para o monitoramento, controle e conservação.

Pode-se observar que a bacia hidrográfica do riacho Rangel apresentou pouca suscetibilidade a ocorrência de enchentes em condições normais de precipitação, ou seja, excluindo-se eventos de intensidade anormais, pelo fato de apresentar valor de coeficiente de compacidade $(\mathrm{Kc})(1,69)$ acima da unidade, ou seja, quanto mais próximo de 1 , maior é a circularidade e mais propicia é a ocorrência de inundação.

TABELA 4 Resultados obtidos para a caracterização morfométrica da bacia do riacho Rangel, no estado do Piauí, Brasil.

\begin{tabular}{ccc}
\hline Características Físicas & Unidade de Medida & Resultados \\
\hline Área $(\mathrm{A})$ & $\mathrm{km}^{2}$ & 326,18 \\
\hline Perímetro $(\mathrm{P})$ & $\mathrm{km}$ & 109,42 \\
\hline Coeficiente de compacidade $(\mathrm{Kc})$ & - & 1,69 \\
\hline Índice de circularidade $(\mathrm{Ic})$ & - & 0,11 \\
\hline Coeficiente de manutenção $(\mathrm{Cm})$ & $\mathrm{m}^{2} / \mathrm{m}$ & 1408,45 \\
\hline Índice de rugosidade $(\mathrm{Ir})$ & $\mathrm{m}$ & 213,00 \\
\hline Fator de forma $(\mathrm{Ff})$ & - & 0,25 \\
\hline Densidade hidrográfica $(\mathrm{Dh})$ & $\mathrm{kmm}^{-2}$ & 0,48 \\
\hline Densidade de drenagem $(\mathrm{Dd})$ & $\mathrm{kmkm}^{-2}$ & 0,71 \\
\hline Índice de sinuosidade $(\mathrm{Is})$ & $\mathrm{kmkm}^{-1}$ & 1,18 \\
\hline Comprimento do rio principal $(\mathrm{L})$ & $\mathrm{km}$ & 42,37 \\
\hline Comprimento total dos canais $(\mathrm{Lt})$ & $\mathrm{km}$ & 231,68 \\
\hline Comprimento vetorial do canal principal $(\mathrm{Lv})$ & $\mathrm{km}$ & 35,95 \\
\hline Amplitudealtimétrica $\left(\mathrm{H}_{\mathrm{m}}\right)$ & $\mathrm{m}$ & 300 \\
\hline Altitude máxima $\left(\mathrm{e}_{\max }\right)$ & $\mathrm{m}$ & 600 \\
\hline Altitude média $\left(\mathrm{e}_{\operatorname{med}}\right)$ & $\mathrm{m}$ & 413 \\
\hline Altitude mínima $\left(\mathrm{e}_{\min }\right)$ & $\mathrm{m}$ & 300 \\
\hline
\end{tabular}

Quanto ao fator de forma $(\mathrm{Ff})$, apresentou valor baixo $(0,25)$. Assim, há uma indicação de que a bacia possui, portanto, uma tendência de forma alongada. Tal fato pode ainda ser comprovado pelo índice de circularidade (IC), possuindo um valor de 0,11 . Analisando os três parâmetros, a bacia apresenta forma comprida, não 
favorecendo a inundação e com topografia favorável ao escoamento superficial, além de ambientalmente com tendência a conservação.

Em bacias de forma circular, há maiores possibilidades de precipitações intensas, pois ocorrerem simultaneamente em toda a extensão da bacia, concentrando grande volume de água no tributário principal, enquanto que em bacias de forma alongada, devido ao menor fator de forma, a precipitação atinge toda a área simultaneamente, evitando concentrações de escoamento superficial (FRAGA et al., 2014).

Fernandes et al. (2018), estudando bacia hidrográfica do rio de ondas, Bahia, obtiveram lc de 0,19 , o que corresponde a $42.11 \%$ maior que a bacia em estudo, e a definiram como: não possui tendências de ocorrências de enchentes. Ataíde et al. (2017) encontraram Ff de 0,38 para bacia do rio Tauá, 33,68\% maior que o obtido para a bacia do riacho Rangel, e o consideram baixo coeficiente e a classificaram como pouco susceptível a enchentes em condições normais de precipitação.

A densidade hidrográfica (Dh) é uma variável de grande importância por representar o comportamento hidrológico de uma determinada área em um de seus aspectos fundamentais, que é a capacidade hídrica e de gerar novos cursos de água, por ser um parâmetro indica a média da quantidade de canais por quilômetro quadrado de uma bacia (VEIGA et al., 2013). Morisawa (1962) utilizou-se da densidade hidrográfica como uma das variáveis na determinação do fator topográfico que indica se a bacia apresenta características favoráveis ou não a inundação.

A Dh obtida revela que existe menos de um canal por $\mathrm{km}^{2}$. Isto indica um ambiente de déficit quanto a drenagem e pouco favorável a geração de novos cursos fluviais. Segundo Lollo (1995), o que causa dificuldade das partículas de água provenientes da precipitação que caem na superfície do solo encontrar rapidamente um canal e por este escoar.

A densidade de drenagem (Dd) se constitui como um dos mais importantes índices a ser considerado na análise quantitativa da bacia, pois, representa o grau de dissecação do relevo e funciona como índice demonstrativo do trabalho fluvial de erosão da superfície. Dessa forma, adquire importância como instrumento de análise da paisagem, sobretudo para a identificação de possíveis focos de susceptibilidade geomorfológica (SOARES et al., 2016).

De acordo com Beltrame (1994), a Dd de uma bacia pode variar entre 0,5 km/ $\mathrm{km}^{2}$ (em bacias com drenagem pobre), 0,5 e $25 \mathrm{~km} / \mathrm{km}^{2}$ (bacias com drenagem mediana), 2,01 $3,5 \mathrm{~km} / \mathrm{km}^{2}$ (bacias bem drenadas) e valores acima de $3,5 \mathrm{~km} / \mathrm{km}^{2}$ (bacias excepcionalmente bem drenadas). O índice de densidade de drenagem encontrado foi de $0,710 \mathrm{~km} / \mathrm{km}^{2}$, indicando que essa região apresenta média capacidade de drenagem. Valores baixos e médios de drenagem, geralmente estão relacionados a regiões de rochas permeáveis e de regime pluviométrico caracterizado por chuvas de baixa intensidade ou pouca concentração de precipitação (TONELLO et al., 2006).

O levantamento do sistema de drenagem da bacia em estudo demonstrou-se de grande relevância ao planejamento do uso e ocupação do solo. Através do método de Strahler (1952) pode-se relacionar que quanto menos ramificada for a rede de drenagem menor será a eficiência na integração entre os diversos componentes e processos que ocorrem no interior da bacia hidrográfica. Os valores encontrados demonstram ramificações de até $4^{a}$ ordem (Tabela 5 ). Nesse sentido, verifica-se que a importância da aplicação de medidas que visam proteger os 
recursos naturais da bacia e buscar equilíbrio com as atividades econômicas ali existentes, como a agropecuária. Dessa forma, numa região como esta, em que a precipitação anual corresponde a quase $50 \%$ do que ocorre no Cerrado de Goiás, por exemplo, a ampliação do Parque Nacional da Serra das Confusões teve função imprescindível para manutenção das atividades agropecuárias em busca de consonância com conservação ambiental.

TABELA 5 Caracterização dos cursos d'água da bacia hidrográfica do Riacho Rangel no estado do Piauí, Brasil.

\begin{tabular}{ccc}
\hline Ordem & Número de canais & Comprimento dos canais (km) \\
\hline 1 & 126 & 119,37 \\
\hline 2 & 26 & 63,76 \\
\hline & 3 & 22,71 \\
\hline 4 & 1 & 25,85 \\
\hline Total & 156 & 231,68 \\
\hline
\end{tabular}

O índice de sinuosidade (Is) é a variável que descreve a velocidade de escoamento do canal do curso hídrico, em que quanto menor a sinuosidade, menor é a dificuldade em que o curso hídrico encontrará para chegar até o exutório, já quando a bacia possuir sinuosidade elevada, maior será a dificuldade (BATISTA et al., 2017). Varia de 1 a 2, indicando que valores próximos ou inferiores a 1 os cursos hídricos são classificados como canais retilíneos, ao passo que valores superiores a 2,0 , indicam cursos de água sinuosos. Valores intermediários sugerem formas transacionais, regulares e irregulares. A bacia apresentou Is de $1,18 \mathrm{~km} \cdot \mathrm{km}^{-1}$, sugerindo, então, que a bacia é classificada como cursos hídricos retilíneos, que é favorável a conservação e preservação da bacia.

O Coeficiente de Manutenção $(\mathrm{Cm})$ representa um índice que visa calcular a área mínima que a bacia precisa dispor para a manutenção de um metro de canal fluvial, sendo o resultado indicado em $\mathrm{m} / \mathrm{m}^{2}$. Na análise realizada no estudo o resultado foi $1408,45 \mathrm{~m}^{2} \cdot \mathrm{m}^{-1}$, ou seja, há necessidade de uma área de drenagem de, no mínimo, $1408,45 \mathrm{~m}^{2} \cdot \mathrm{m}^{-1}$ para a manutenção de um metro de canal de escoamento.

Os dados obtidos pelo $\mathrm{Cm}$ são elevados, o que necessita de uma área considerável para a manutenção (área de recarga) e evolução da drenagem. Estes resultados podem ser corroborados pela densidade de drenagem e hidrográfica, os quais foram baixos, sugerindo que a bacia possui dificuldade na renovação e formação de novos canais. Essa realidade pode ser entendida ao verificar que a bacia apresenta baixas declividades e baixos índices de rugosidade, fatores de grande relevância no escoamento fluvial e formação de canais novos.

O índice de rugosidade (Ir) relaciona a disponibilidade do escoamento hídrico superficial com o potencial erosivo, expresso pela declividade média, ou seja, quanto maior for esse índice, maior será o risco de degradação da bacia quando as vertentes são íngremes e longas. $O$ valor do Ir calculado para bacia em questão resultou em $213 \mathrm{~m}$, que é considerado alto, e atribuído esse resultado a elevada amplitude altimétrica (300) favorecendo acentuado escoamento superficial e processos erosivos. 


\section{CONCLUSÕES}

As características de uso e cobertura do solo em 2017 evidenciam que o Cerrado ocupa $63 \%$ da bacia do riacho Rangel $(\mathrm{PI})$. A declividade da bacia informa que o relevo é predominante de baixo declive, com características favoráveis para as práticas agrícolas como agricultura, pastagens, culturas anuais, dentre outros. A amplitude altimétrica de mínima de $300 \mathrm{~m}$ e máxima de $600 \mathrm{~m}$ podem provocar alterações na temperatura média, que associado ao baixo índice pluviométrico pode ocasionar em dificuldade de desenvolvimento de determinadas culturas agrícolas.

A bacia hidrográfica do riacho Rangel é de quarta ordem, sendo seu sistema de drenagem bem ramificado, possui forma alongada, que pode ser comprovada pelos índices de compacidade, circularidade e fator de forma, sinalizando pouca suscetibilidade a enchentes em condições normais de pluviosidade anual.

A densidade de drenagem é classificada como baixo, com médio sistema de drenagem e precipitação pluviométrica anual baixa. Esse parâmetro tem grande influência sobre o escoamento superficial e, consequentemente, sobre o processo de erosão e inundação e atestam que escoamento da água na bacia em questão é lento.

A rugosidade apresentada na bacia sugere acentuado escoamento superficial e as ocorrências erosivas para estes compartimentos, implicando em práticas conservacionistas do solo. Os resultados alcançados nesse trabalho podem possibilitar novas perspectivas quanto a medidas de planejamento estratégico e gestão dos recursos hídricos.

\section{REFERÊNCIAS}

ALVES SOBRINHO, T.; OLIVEIRA, P. T. S.; RODRIGUES, D., B. B.; AYRES, F. M. Delimitação automática de bacias hidrográficas utilizando dados SRTM. Revista Engenharia Agrícola, Jaboticabal, v. 30, n. 1, p. 46-57, 2010. URL: http://www.scielo.br/scielo.php?pid=S0100-

69162010000100005\&script=sci_abstract\&tIng=pt/_ DOI: 10.1590/S010069162010000100005 .

ATAÍDE, L. C. P.; RODRIGUES, R. S. S.; PESSOA, F. C. L. Caracterização morfométrica da bacia hidrográfica do rio Tauá, Nordeste Paraense. Revista Brasileira de Gestão Ambiental, v. 11, n. 1, p. 130-138, 2017. Disponível em: http://www.gvaa.com.br/revista/index.php/RBGA/article/view/4943/ Doi: 10.18378/rbga.v11i1.4943.

BARRETO, K. T.; PINTO, M. L. C. Caracterização dos Indicadores Geomorfológicos na Bacia Hidrográfica do Rio Verde, Ponta Grossa - PR. Geografia, Ensino \& Pesquisa, v. 21, n.2, p. 164-173, 2017. Disponível em: https://periodicos.ufsm.br/geografia/article/viewFile/24088/pdf/_ Doi: $10.5902 / 2236499424088$

BATISTA, D. F.; CABRAL, J. B. P.; ROCHA, T.; BARBOSA, G. R. Caracterização morfométrica da bacia hidrográfica do Ribeirão Santo Antônio - GO. Revista Geoambiente, n. 29, p. 15-35, 2017. Disponível em: http://www.revistas.ufg.br/geoambiente/article/view/50882/24886/ Doi: 10.5216/revgeoamb.v0i29.50882. 
BELTRAME, A. V. Diagnóstico do meio ambiente físico de bacias hidrográficas: modelo de aplicação. Florianópolis: UFSC, 112 p. 1994.

BOTELHO, R. G. Erosão e conservação dos solos: conceitos, temas e aplicações (org.). Rio de Janeiro: Bertrand Brasil, 269-300 p. 2015.

BOTREL, R.; BRITO, D. R. S.; SOUSA, W. C.; SOUZA, A. M.; HOLANDA, A. C. Fenologia de uma espécie arbórea em ecótono Caatinga / Cerrado no sul do Piauí. Revista Verde de Agroecologia e Desenvolvimento Sustentável, v. 10, n. 3, p. 07-12, 2015.2 Disponível em: https://www.gvaa.com.br/revista/index.php/RVADS/article/view/3587/3247/ Doi: 10.18378/rvads.v10i3.3587.

BRASIL. Decreto de 30 de dezembro de 2010. Dispõe sobre a ampliação do Parque Nacional da Serra das Confusões. Diário Oficial da União, Brasília, DF, seção1 - edição extra, № 250-A, p. 13-17, 2010. Disponível em: http://legislacao.planalto.gov.br/legisla/legislacao.nsf/Viw_Identificacao/dsn\%203012-2-2010?OpenDocument.

CARVALHO, A. H. O.; CASTRO, F. S.; PENA, F. E. R. Caracterização morfométrica da bacia hidrográfica do córrego Santa Maria, Ibatiba-ES. Nucleus, v. 11, n. 2, p. 317-324, $2014 . \quad$ Disponível em: http://www.nucleus.feituverava.com.br/index.php/nucleus/article/view/1161/_ Doi: 10.3738/1982.2278.1161.

CHRISTOFOLETTI, A. A Análise de Bacias Hidrográficas. São Paulo: Geomorfismo, p. 102 - 121.1980.

FERNANDES, F.; OLIVEIRA, M. S. C.; ROCHA, F. A. Análise das características morfométricas da bacia hidrográfica do rio de Ondas, BA. Revista Científica Multidisciplinar Núcleo do Conhecimento, v. 2, n. 2, p. 55-71, 2018. Disponível em: $\quad$ https://www.nucleodoconhecimento.com.br/geografia/caracteristicasmorfometricas-da-bacia-hidrografica.

FRAGA, M. S.; FERREIRA, R. G.; SILVA, F. B.; VIEIRA, N. P. A.; SILVA, D. P.; BARROS, F. M.; MARTINS, I. S. B. Caracterização morfométrica da bacia hidrográfica do Rio Catolé Grande, Bahia, Brasil. Nativa, v. 2, n. 4, p. 214-218, 2014. Disponível http://periodicoscientificos.ufmt.br/ojs/index.php/nativa/article/view/1785/ Doi: 10.14583/2318-7670.v02n04a05.

GERBER, D.; PERTILLE, C. T.; VIEIRA, F. S.; CORRÊA, B. J. S.; SOUZA, C. F. Caracterização morfométrica da Bacia Hidrográfica do Rio Itajaí - Santa Catarina. Acta Biológica Catarinense, v. 5, n. 1, p. 72-83, 2018. Disponível em: http://periodicos.univille.br/index.php/ABC/article/view/446/ http://dx.doi.org/10.21726/abc.v5i1.446.

GUIMARÃES, G. S. C. Parâmetros físico-químicos das águas da bacia do alto rio Gurguéia e sub-bacia do rio Contrato, Piauí. Programa de Pós-Graduação em 
Agronomia: Solos e nutrição de plantas, Universidade Federal do Piauí, 2014. 50 p. Dissertação de Mestrado.

IBGE. Instituto Brasileiro de Geografia e Estatística . Área territorial oficial. Resolução da Presidência do IBGE de n 5 (R.PR-5/02). Acesso em 12 de dezembro de 2017.

LOLLO, J. A. O uso da técnica de avaliação do terreno no processo de elaboração do mapeamento geotécnico: sistematização e aplicação na quadrícula de Campinas. Escola de Engenharia de São Carlos, Universidade de São Paulo. São Carlos, 1995. 268 p. Tese (Doutorado em Geotecnia).

MIOTO, C. L., OLIVEIRA, R. V., QUEIROZ, S. D. M., PEREIRA, T. V., ANACHE, J. A. A.; PARANHOS, F. A. C. Morfometria de bacias hidrográfcas através de SIGs livres e gratuitos. Anuário do Instituto de Geociências, v. 37, n. 2, p. 16-22, 2017. Disponível em: http://www.ppegeo.igc.usp.br/index.php/anigeo/article/view/5996/ Doi: 10.11137/2014_2_16_22.

MIRANDA, E. E. de; (Coord.). Brasil em Relevo. Campinas: Embrapa Monitoramento por Satélite, 2005.2 Disponível em: http://www.relevobr.cnpm.embrapa.br. Acesso em: 2 dez. 2015.

MORISAWA, M. E. Qualitative geomorphology of some watersheds in the Appalachian Plateau. Geological Society of America Bulletin, v. 73, n. 9, p. 10251046, 1962. Disponível em: https://pubs.geoscienceworld.org/gsa/gsabulletin/articleabstract/73/9/1025/5476/ Doi: 10.1130/0016-7606(1962)73[1025:QGOSWI]2.0.CO;2.

NARDINI, R. C.; POLLO, R. A.; CAMPOS, S.; BARROS, Z. X. D.; CARDOSO, L. G.; GOMES, L. N. Análise morfométrica e simulação das áreas de preservação permanente de uma microbacia hidrográfica. Irriga, v.18, n.4, p. 687-699, 2013. Disponível em: http://revistas.fca.unesp.br/index.php/irriga/article/view/669/ Doi: 10.15809/irriga.2013v18n4p687.

ROCHA, R. M.; LUCAS, A. A. T.; AlMEIDA, C. A. P.; NETO, E. L. M.; NeTTO, A. O. A. Caracterização morfométrica da sub-bacia do rio Poxim-Açu, Sergipe, Brasil. Ambiente \& Água, v. 9, n. 2, p. 276-287, 2014. Disponível em: http://www.scielo.br/scielo.php?pid=S1980993X2014000200009\&script=sci_abstract \&tlng=pt/ Doi: 10.4136/ambi-agua.1289.

SANTOS, A. M.; TARGA, M. S.; BATISTA, G. T.; DIAS, N. W. Análise morfométrica das sub-bacias hidrográficas Perdizes e Fojo no município de Campos do Jordão, SP, Brasil. Ambiente \& Água, v. 7, n.3, p. 195-211, 2012. Disponível em: http://www.scielo.br/pdf/ambiagua/v7n3/v7n3a16/ Doi: 10.4136/ambi-agua.945.

SCHUMM, S.A. Evolution of drainage systems and slopes in badlands at Perth Amboy, New Jersey. Geological Society of America Bulletin, v. 67, n.5, p. 597646. 1956. Disponível em: http://adsabs.harvard.edu/abs/1956GSAB...67..597S/ Doi: 10.1130/0016-7606(1956)67[597:EODSAS]2.0.CO;2. 
SOARES, L. S.; LOPES, W. G. R.; CASTRO, A . C. L.; ARAUJO, G. M. C.; ARAÚJO, G. M. C. Análise morfométrica e priorização de bacias hidrográficas como instrumento de planejamento ambiental integrado. Revista do Departamento de Geografia, v. 31, p. 82-100, 2016. Disponível em: http://www.revistas.usp.br/rdg/article/view/107715/ Doi: 10.11606/rdg.v31i0.107715.

SILVA, A. R.; SILVA, M. F.; SANTOS, L. C. A. Caracterização morfométrica da bacia hidrográfica do Rio Cacau (MA). Revista Percurso - Nemo, v. 6, n. 2, p. 141-153, 2014. Disponível

em: http://www.periodicos.uem.br/ojs/index.php/Percurso/article/view/24262/_Doi: 10.4025/revpercurso.v6i2.24262.

STRAHLER, A.N. Hypsometric Area-altitude: analysis and erosional topography. Geological Society of America Bulletin, v. 63, n. 10, p. 1117-1142, 1952. Disponível em: https://pubs.geoscienceworld.org/gsa/gsabulletin/articleabstract/63/11/1117/4477/hyp sometric-area-altitude-analysis-of-erosional?redirectedFrom=fulltext/2 Doi: 10.1130/0016-7606(1952)63[1117:HAAOET]2.0.CO;2.

TEODORO, V. L. I.; TEIXEIRA, D.; COSTA, D. J. L.; FULLER, B. B. O conceito de bacia hidrográfica e a importância da caracterização morfométrica para o entendimento da dinâmica ambiental local. Revista Uniara, v. 11, n. 20, p. 137-156. 2007.

Disponível

em:

http://www.revistarebram.com/index.php/revistauniara/article/view/236/ Doi: https:10.25061/2527-2675/ReBraM/2007.v1111.236.

TONELLO, K. C.; DIAS, H. C. T.; SOUZA, A. L.; RIBEIRO, C. A. A. S.; LEITE, F. P. Morfometria da bacia hidrográfica da Cachoeira das Pombas, Guanhães - MG. Revista Árvore, v. 30, n. 5, p. 849-857, 2006. Disponível em: http://www.scielo.br/scielo.php?script=sci_arttext\&pid=S0100-67622006000500019 Doi: 10.1590/S0100-67622006000500019.

VASCO, A. N.; BRITTO, F. B.; PEREIRA, A. P. S.; MÉLLO, J. A. V.; GARCIA, C. A. B.; NOGUEIRA, L. C. Avaliação espacial e temporal da qualidade da água na subbacia do Rio Poxim, Sergipe, Brasil. Ambiente \& Água, v. 6, n.1, p. 118-130. 2011. Disponível em: http://www.researchgate.net/publication/273437818_Avaliacao_espacial_e_temporal da_qualidade_da_agua_na_sub-bacia_do_rio_Poxim_Sergipe_Brasil/ ${ }^{-}$Doi: 10.4136/ambi-agua.178.

VEIGA, A. M.; TRINDADE, M. C.; SOUZA, R. M.; OLIVEIRA, W. N. Caracterização hidromorfológica da bacia do rio dos Bois. In Simpósio Brasileiro de Recursos Hídricos, 10, Anais...Porto Alegre, 2013. 